\title{
The Frank-Starling relationship of the heart revealed in a large animal study utilizing real-time undersampled radial MRI at variable inotropic state and heart rate
}

\author{
Walter R Witschey ${ }^{1 *}$, Francisco Contijoch¹, Jeremy R McGarvey ${ }^{1}$, Victor A Ferrari ${ }^{1}$, Michael Hansen², Julio Chirinos ${ }^{1}$, \\ Paul Yushkevich1, Joseph H Gorman', Robert C Gorman', James J Pilla'
}

From 17th Annual SCMR Scientific Sessions

New Orleans, LA, USA. 16-19 January 2014

\section{Background}

LV performance is coupled to loading conditions (i.e. preload and afterload) and myocardial contractility $(1,2)$. Therefore load-independence is an important means to isolate and study LV contractility in preclinical studies of cardiovascular pharmaceuticals and devices (3). Precise and rapid assessment of LV pressure is achieved with high fidelity catheter-based pressure transducers but measurements of LV volume are more difficult and less reliable. Thus far, MRI has not demonstrated sufficient spatiotemporal resolution to measure beat-to-beat changes of the pressure-volume (PV) loop to measure left ventricular (LV) elasticity or preload-recruitable stroke work (PRSW). Our aim was to develop a realtime (rtMRI) approach to measure PV and FrankStarling relationships in a preclinical model of heart disease under normal and stressed physiologic conditions.

\section{Methods}

The University of Pennsylvania IACUC approved all experiments. Yorkshire swine $(\mathrm{n}=8)$ were anesthetized and instrumented with expandable vascular occluders placed at the inferior $(20 \mathrm{~mm})$ and superior $(24 \mathrm{~mm})$ vena cavae and transiently inflated during simultaneous rtMRI and intraventricular pressure measurement. Images were reconstructed with non-Cartesian parallel SENSE and $>10 \mathrm{k}$ frames were segmented in $<5 \mathrm{~min}$ with semi-automatic active contours.

${ }^{1}$ Surgery, University of Pennsylvania, Philadelphia, Pennsylvania, USA Full list of author information is available at the end of the article

\section{Results}

The relationship between $\mathrm{Te}, \mathrm{Tr}$ and ejection fraction is shown (Figure 1a, b). We found PV loops could be accurately measured using an image exposure time $\mathrm{Te}<$ $100 \mathrm{~ms}(<34$ projections $)$ and frame rate $\mathrm{Tr}<50 \mathrm{~ms}$ (view sharing $<17$ projections) at elevated heart rates $(\sim 140 \mathrm{bpm})$. With an optimized exposure time $(\mathrm{Te}=$ $95 \mathrm{~ms}$ and frame rate $\operatorname{Tr}=2.8 \mathrm{~ms}$ ), we found that there was no significant difference between cine and rtMRI at rest in end-diastolic volume (EDV), end-systolic volume (ESV), ejection fraction (EF), stroke volume (SV) or cardiac output $(\mathrm{CO})(\mathrm{n}=8, \mathrm{p}<0.05)$ at either normal or elevated heart rates (table 1). A representative PV loop at rest and elevated inotropy is shown (Figure 1d). EES increased from $1.9 \pm 0.7$ to $3.1 \pm 0.3 \mathrm{mmHg} / \mathrm{mL}(\mathrm{n}=8$, $\mathrm{p}<0.05)$. There was decreased stroke work (SW) under reduced loading conditions (Frank-Starling mechanism); PRSW was highly linear $(\mathrm{r}=0.98)$ and increased from $6.2 \pm 1.2$ to $9.1 \pm 0.9 \mathrm{mmHg}$ during continuous IV dobutamine $(\mathrm{n}=8, \mathrm{p}<0.05)$. There was no significant difference in the $\mathrm{LV}$ volume at zero pressure V0 $(\mathrm{n}=8, \mathrm{p}<0.05)$.

\section{Conclusions}

RtMRI can accurately assess LV volumes, elasticity and PRSW at baseline and elevated inotropic state, providing non-invasive into the Frank-Starling relationship of the intact heart.

\section{Funding}

The authors gratefully acknowledge support from the National Institutes of Health through awards K99HL108157 and R01HL63904. 


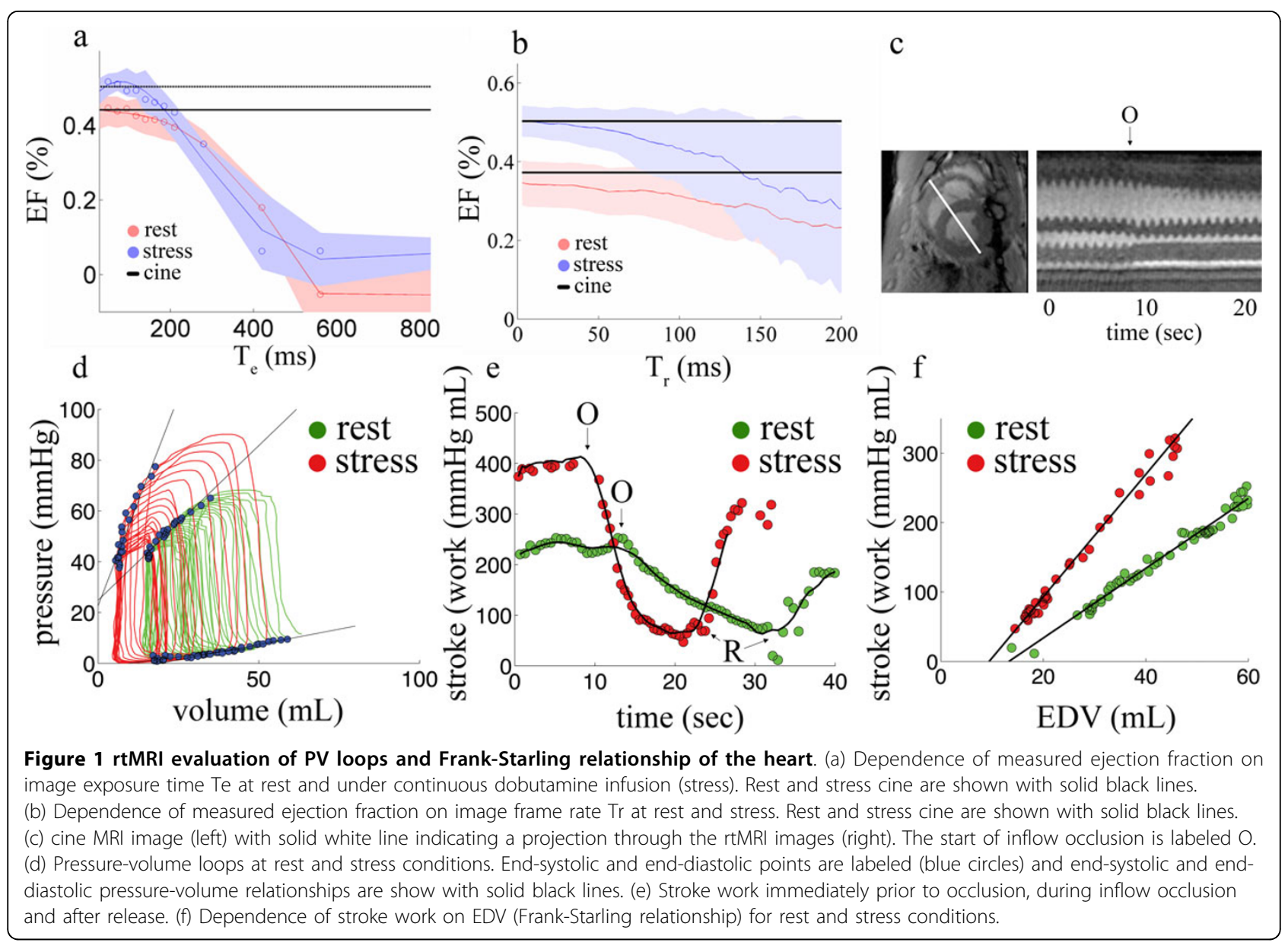

Table 1 Real-time and cine-MRI derived LV hemodynamic and elastic properties

\begin{tabular}{|c|c|c|c|c|}
\hline & $\begin{array}{c}\text { Real-Time MRI } \\
\text { (rest) }(\mathrm{n}=5)\end{array}$ & $\begin{array}{l}\text { Real-Time MRI } \\
\text { (stress) }(\mathrm{n}=5) \\
\end{array}$ & $\begin{array}{c}\text { Cine MRI } \\
\text { (rest) }(n=5)\end{array}$ & $\begin{array}{c}\text { Cine MRI } \\
\text { (stress) }(n=5)\end{array}$ \\
\hline Heart rate (bpm) & $112.1+-22.9^{*}$ & $140.2+-20.2^{*}$ & $116.8+-21.1$ & $147.6+-16.1$ \\
\hline EDV $(\mathrm{mL})$ & $57.9+-13.2$ & $47.0+-5.2$ & $61.1+-10.7$ & $54.1+-5.7$ \\
\hline ESV (mL) & $35.3+-7.1^{*}$ & $23.6+-4.1^{*}$ & $35.8+-8.0$ & $25.3+-10.7$ \\
\hline $\mathrm{SV}(\mathrm{mL})$ & $22.7+-8.3$ & $23.4+-7.5$ & $25.3+-5.8$ & $28.9+-3.7$ \\
\hline EF (\%) & $38+-9^{*}$ & $49+-11^{*}$ & $41+-7$ & $53+-3$ \\
\hline $\mathrm{CO}(\mathrm{L} / \mathrm{min})$ & $2.6+-0.7$ & $3.2+-0.9$ & $2.9+-0.6$ & $3.3+-1.0$ \\
\hline Eed $(\mathrm{mmHg} / \mathrm{mL})$ & $0.3+-0.13$ & $0.28+-0.19$ & N/A & N/A \\
\hline Ees $(\mathrm{mmHg} / \mathrm{mL})$ & $1.9+-0.7^{*}$ & $3.1+-0.3^{*}$ & N/A & N/A \\
\hline V0 (mL) & $-8.1+-13.8$ & $-1.9+-4.1$ & N/A & N/A \\
\hline Stroke work (mmHg mL) & $221.3+-51.9^{*}$ & $306.9+-96.4^{*}$ & N/A & N/A \\
\hline PRSW (mmHg) & $6.2+-1.2$ & $9.1+-0.9$ & N/A & N/A \\
\hline
\end{tabular}

${ }^{*} \mathrm{p}<0.05$ paired t-test, N/A (not applicable) cine measures of elasticity and work were not possible to measure/not measured.

\section{Authors' details}

${ }^{1}$ Surgery, University of Pennsylvania, Philadelphia, Pennsylvania, USA.

${ }^{2}$ National Institutes of Health, Bethesda, Maryland, USA.

Published: 16 January 2014
doi:10.1186/1532-429X-16-S1-P57

Cite this article as: Witschey et al.: The Frank-Starling relationship of the heart revealed in a large animal study utilizing real-time undersampled radial MRI at variable inotropic state and heart rate. Journal of Cardiovascular Magnetic Resonance 2014 16(Suppl 1):P57. 